\title{
Applications on Thermostable Polar Capillary GC Columns
}

\author{
By M.T. Rodríguez-Estrada ${ }^{1 *}$, N. Frega ${ }^{2}$ and G. Lercker ${ }^{1}$ \\ ${ }^{1}$ Dept. Scienze degli Alimenti, Università degli Studi di Bologna, \\ viale Fanin 40, 40126 Bologna \\ ${ }^{2}$ Dept. Biotecnologie Agrarie e Ambientali, Università degli Studi di Ancona, \\ via Brecce Bianche, 60131 Ancona - Italy \\ *Tel. +39-051-2096011, Fax +39-051-2096017, Email: estrada@sun.economia.unibo.it
}

\section{CONTENTS}

1. Introduction

2. Analysis of total lipids

2.1. Analysis of triacylglycerols (triglycerides).

2.2. Analysis of diacylglycerols (diglycerides).

2.3. Analysis of monoacylglycerols (monoglycerides).

2.4. Analysis of fatty acids.

2.5. Analysis of the unsaponifiable components.

2.5.1. Tocopherols and tocotrienols.

2.5.2. Linear and triterpenic alcohols.

2.5.3. Diterpenic alcohols.

2.5.4. Sterols (4-desmethylsterols).

2.5.5. Sterol oxidation products.

References.

\section{RESUMEN}

Aplicaciones de columnas capilares polares termoestables en cromatografía gaseosa.

La composición, el efecto del procesamiento y el almacenamiento, y la calidad total de los alimentos grasos se pueden evaluar por cromatografía de gases (GC). El análisis cromatográfico se lleva a cabo con columnas capilares polares y apolares que separan los diferentes componentes lipídicos de acuerdo a su polaridad y punto de ebullición. Sin embargo, existen componentes con altos puntos de ebullición que requieren temperaturas más elevadas para lograr una mejor separación. Las columnas polares termoestables de cromatografía de gases con un "sangrado" relativamente bajo, se pueden usar para esta actividad. Estas columnas generan cromatogramas con características diferentes que pueden conducir a la identificación de componentes que no pueden ser completamente resueltos con columnas no polares. Las columnas polares termoestables de cromatografía de gases son óptimas para la separación de las diferentes clases de lípidos y pueden ser usadas para una visión rápida del total de la materia insaponificable del aceite o extracto lipídico. En este artículo se describen una serie de ejemplos de análisis de los lípidos de diferentes alimentos, llevados a cabo con columnas termoestables de cromatografía de gases.

PALABRAS-CLAVE: Columnas polares - Columnas termoestables - Cromatografía de gases - Fracción insaponificable - Lípidos.

\section{SUMMARY}

Applications on thermostable polar capillary GC columns.

The composition, the effect of processing and storage, and the overall quality of food lipids can be evaluated by gas chromatography (GC). GC analyses are carried out on non-polar or polar capillary columns, which separate the various lipid components according to their polarity and boiling points. However, there are components with high-boiling points that require higher temperatures in order to be better resolved. Thermostable polar GC columns with a relatively low column bleeding, can be used for this scope. These columns generate GC traces with different separation characteristics, which can lead to the identification of components that cannot be completely resolved with non-polar GC columns. Thermostable polar GC columns are suitable for the separation of different lipid classes and can be utilised for a fast screening of the total unsaponifiable matter of the oil or lipid extract. A series of examples for the analysis of food lipids with thermostable polar GC columns, are here described.

KEY-WORDS: Gas chromatography - Lipids - Polar columns Thermostable columns - Unsaponifiable fraction.

\section{INTRODUCTION}

The composition, the effect of processing and storage, and the overall quality of food lipids can be evaluated by means of chemical, physical-chemical and sensory analysis. Among the analytical techniques used for this scope, gas chromatography (GC) is one of the most popular, due to its versatility and the reliability of the qualitative and quantitative results that it provides. In addition, the results are obtained in short time, which makes it suitable for quality control purposes.

GC of food lipids can be performed on the lipids as such or after extraction, fractionation and/or purification by thin-layer chromatography (TLC), high-performance liquid chromatography (HPLC) and/or solid phase extraction (SPE). The scope of the lipid fractionation and purification steps is to produce a clean, enriched fraction that contains the compounds of interest, thus facilitating their separation in GC and reducing the risk of peak overlapping.

GC analysis can be carried out on non-polar or polar capillary columns, which separate the various lipid components according to their polarity and boiling points. GC capillary columns with opposite polarity can result in different peak resolution, thus 
providing a complementary picture of the lipid matrix. However, there are components with high-boiling points that require high temperatures in order to be better resolved. Column manufacturers have been able to produce polar GC capillary columns that can operate at high temperatures, with a relatively low column bleeding. The end-chain degradation of the polysiloxanes and the consequent cross-linking do not occur, so that no changes in the film thickness, selectivity and polarity of the column are observed. These columns have $50-65 \%$ of polar stationary phase (such as phenyl- or diphenyl-siloxane) and $35-50 \%$ of non-polar ones (such as dimethyl-siloxane); these particular blends of stationary phases have proven to be suitable for the separation of different lipid classes.

\section{ANALYSIS OF TOTAL LIPIDS}

A preliminary screening of the lipid composition is usually performed by silica TLC (Morris et al. 1968), which is a rapid and inexpensive method. The total lipids or the single TLC (or HPLC) fraction can be directly injected on a thermostable polar GC column with a 65\% phenyl-35\% dimethyl-polysiloxane stationary phase $(25 \mathrm{~m} \times 0.25 \mathrm{~mm}$ i.d. $\times 0.1 \mu \mathrm{m}$ film thickness) (TAP column, Chrompack, Middelburg, The Netherlands). The lipids can also be transmethylated and then injected into the same column, so as to analyse the fatty acid composition in depth or each lipid fraction in detail. In general, the oven temperature is programmed from $200^{\circ} \mathrm{C}$ to
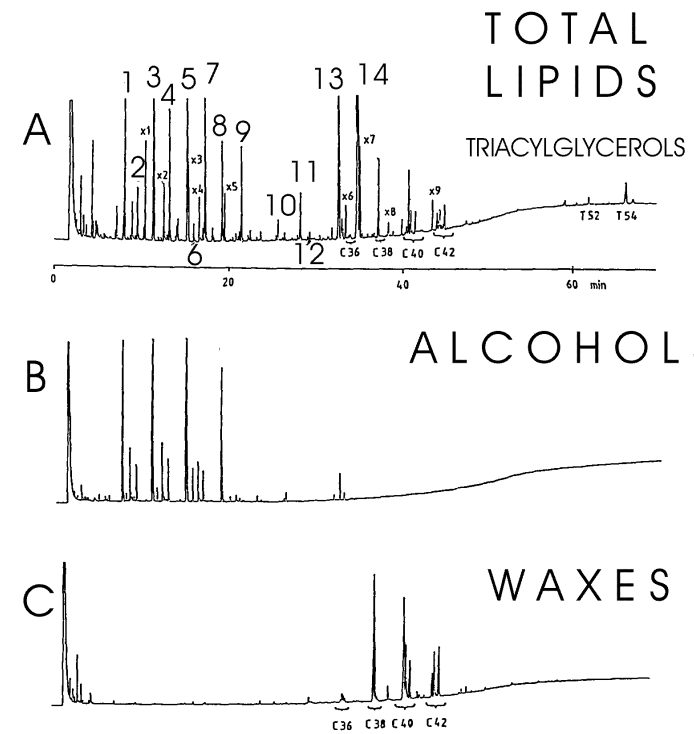

Figure 1

$\mathrm{GC}$ traces of the total lipids (A) and the TLC fractions of fatty alcohols (B) and waxes (C), extracted from the olive drupe skin Note: Peaks 1, 3, 5 and 8 are linear alcohols with 20, 22, 24, and 26 carbon atoms, respectively; $\mathrm{Cnm}$ and Tnm are waxes and triglycerides, respectively, $\mathrm{nm}$ being the carbon atom numbers.

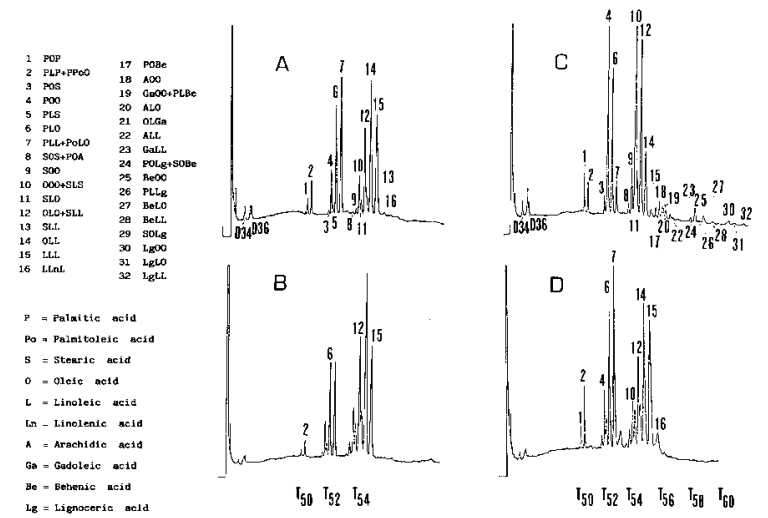

Figure 2

$\mathrm{GC}$ traces of total lipids of corn oil (A), sunflower oil (B), peanut oil (C) and soybean oil (D).

Note: Dnm and Tnm mean diglycerides and triglycerides, respectively, $\mathrm{nm}$ being the carbon atom numbers. (From Frega et al. (1990), with permission).

$350^{\circ} \mathrm{C}$ at $3^{\circ} \mathrm{C} / \mathrm{min}$, where it is held for $20 \mathrm{~min}$. Helium flow rate and split ratio are $0.8 \mathrm{~mL} / \mathrm{min}$ and $1: 80$, respectively. Both injector and detector temperatures are set up at $350^{\circ} \mathrm{C}$. TLC mobile phase is $n$-hexane:diethyl ether $(60: 40, \mathrm{v} / \mathrm{v})$. Figure 1 shows chromatograms of the lipid composition of the olive drupe skin (Frega et al. 1993b), applying slightly different analytical conditions: oven temperature was programmed from $200^{\circ} \mathrm{C}$ to $360^{\circ} \mathrm{C}$ at $3^{\circ} \mathrm{C} / \mathrm{min}$, injector and detector temperatures were set up at $350^{\circ} \mathrm{C}$ and helium flow rate was $1 \mathrm{~mL} / \mathrm{min}$. Low amounts of waxes were detected in both matrices, whereas high contents of triterpenic alcohols, long chain fatty acids and linear alcohols were observed.

\subsection{Analysis of triacylglycerols (triglycerides)}

Excellent triglyceride peak resolutions have been achieved with the TAP column (Frega et al. 1990) on the basis of the triglyceride carbon number and the degree of unsaturation of the single triglyceride. Figure 2 shows the profile of some edible oils obtained with slightly different analytical conditions: oven temperature was programmed from $340^{\circ} \mathrm{C}$ to $360^{\circ} \mathrm{C}$ at $1{ }^{\circ} \mathrm{C} / \mathrm{min}$, injector and detector temperatures were set up at $400^{\circ} \mathrm{C}$ and helium flow rate was 1 $\mathrm{mL} / \mathrm{min}$. (Frega et al. 1990). The separation efficiency attained with this thermostable polar column is, in fact, comparable to that obtained by HPLC (Dong and Dicesare 1983; Palmer and Palmer 1989). This type of analysis can be particularly useful for quality control of edible oils, butter fat, dairy spreads, cocoa butter, cocoa butter equivalents, coffee, animal fat (chicken, egg-yolk), tobacco seeds (Frega et al. 1991). 


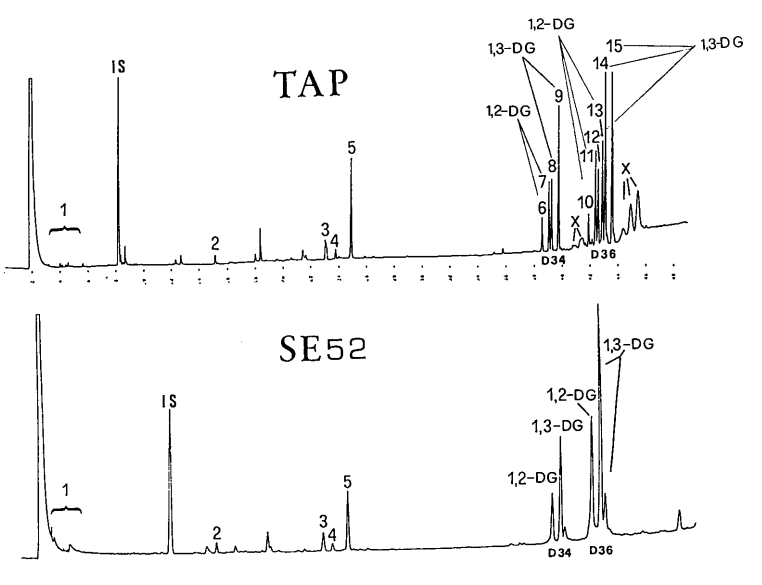

Figure 3

GC traces of the diglyceride composition of sunflower oils, obtained with a polar (TAP) and a non-polar (SE52) columns.

Note: 1 , free fatty acids; IS, internal standard; 2 , squalene; 3 , campesterol; 4, stigmasterol; 5 , sitosterol; 6 and 7, 1,2-diglycerides with 34 carbon atoms (without considering glycerine); 8 and 9, 1,3-diglycerides with 34 carbon atoms (without considering glycerine); 10,11 and 13 , 1,2-diglycerides with 36 carbon atoms (without considering glycerine);

12,14 and 15, 1,3-diglycerides with 36 carbon atoms (without considering glycerine); $\mathrm{X}, \mathrm{C}_{16}$ - and $\mathrm{C}_{18}$-steryl esters. (From Frega et al. (1993c), with permission).

\subsection{Analysis of diacylglycerols (diglycerides)}

The TAP column also provides high efficient GC separations of the diglycerides (DG) (Frega et al. 1993c). This column is able to separate 1,2-DG from 1,3-DG, which not easy to get when using a non-polar GC column. Figure 3 shows the GC traces of diglycerides obtained with polar (TAP) and non-polar (SE52) columns. The GC conditions used for the TAP column $(25 \mathrm{~m} \times 0.25 \mathrm{~mm}$ i.d. $\times 0.1 \mu \mathrm{m}$ film thickness) have been described in the section about analysis of total lipids, whereas those employed for the SE52 column $(25 \mathrm{~m} \times 0.32 \mathrm{~mm}$ i.d. $\times 0.1 \mu \mathrm{m}$ film thickness) (Mega, Legnano, Milan, Italy) were as follows: the oven temperature was programmed from $180^{\circ} \mathrm{C}$ to $350^{\circ} \mathrm{C}$ at $3^{\circ} \mathrm{C} / \mathrm{min}$ and then held at $350^{\circ} \mathrm{C}$ for $20 \mathrm{~min}$; the helium flow rate and split ratio were 0.6 $\mathrm{mL} / \mathrm{min}$ and $1: 80$, respectively, and both injector and detector temperatures were set up at $350^{\circ} \mathrm{C}$. This kind of analysis has enlightened the importance of the determination of the ratio between these two types of DG for the quality control of the olive oil (Frega et al. 1993e) and crude oils before refining (Frega et al. 1993c). This ratio could be used as index for oil quality as diglycerides are partially removed in the refining process. The determination of DG with thermostable columns has also been used for monitoring lipolysis in olive oils and frying oils (Penazzi et al. 1996), as well as for studying the stability of veiled extra-virgin olive oils (Lercker et al. 1994).

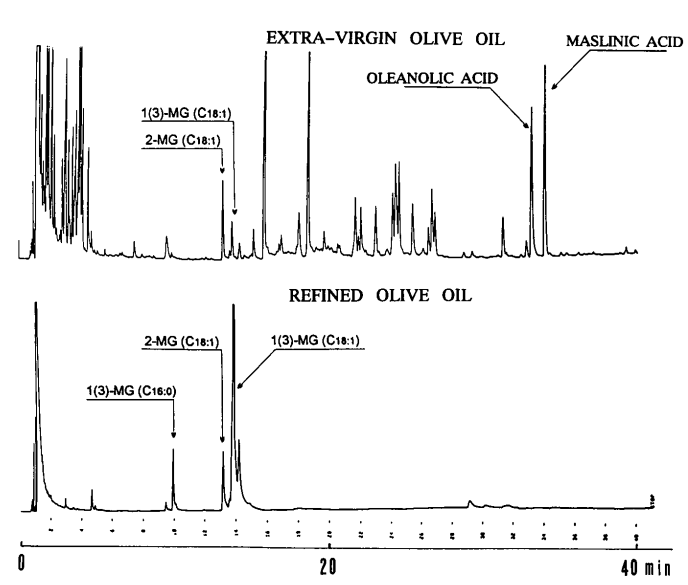

Figure 4

GC traces of the monoglyceride composition of extra virgin and refined olive oils.

Note: MG, monoglyceride (Frega, unpublished results).

\subsection{Analysis of monoacylglycerols (monoglycerides)}

The determination of the composition of fatty acids in the central position of glycerine, after enzymatic treatment with pancreatic lipase, is useful for the identification of chemically esterified lipids. The direct analysis of the trimethylsilyl derivatives of the monoglycerides is a fast method and exhibits least interference as compared with the official method (Lercker et al. 1985). Figure 4 shows the GC traces of the TMS derivatives of the polar minor components of an extra virgin olive oil and a refined olive oil, obtained by using a thermostable polar GC column. The oven temperature was programmed from 200 to $360^{\circ} \mathrm{C}$ at $3^{\circ} \mathrm{C} / \mathrm{min}$; the injector and detector temperatures were set at $360^{\circ} \mathrm{C}$ and helium flow rate was $1 \mathrm{~mL} / \mathrm{min}$.

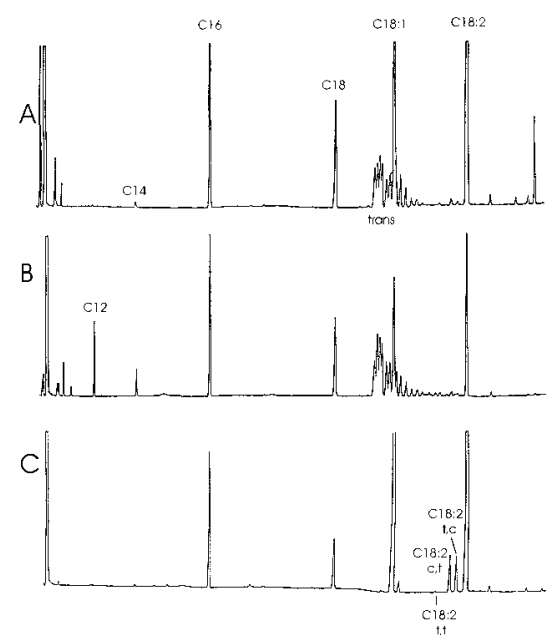

Figure 5

$\mathrm{GC}$ traces of the fatty acid methyl esters of vegetal margarines $(A$ and $B)$ and sunflower oil (C).

Note: $\mathrm{c}$, cis; $\mathrm{t}$, trans (Frega, unpublished results). 


\subsection{Analysis of fatty acids}

The total fatty acid composition is the most common GC determination, which is usually performed on thermostable GC columns. Total fatty acid methyl esters can be analysed with polar GC columns (OV 275, 285) as these stationary phases provide a good separation of the trans-isomers. For example, the GC conditions for an OV275 column (30 m x $0.25 \mathrm{~mm}$ i.d. $\times 0.2 \mu \mathrm{m}$ film thickness) can be as follows: oven temperature programmed from $130^{\circ} \mathrm{C}$ to $200^{\circ} \mathrm{C}$ at a rate of $3^{\circ} \mathrm{C} / \mathrm{min}$, helium flow rate at $1.4 \mathrm{~mL} / \mathrm{min}$ and the injector and detector temperatures set up at $220^{\circ} \mathrm{C}$. In fact, the use of thermostable polar columns is part of an official EC method for the evaluation of virgin olive oil purity (EC 1991). Figure 5 shows how $100-\mathrm{m}$ columns with the cited stationary phase can further improve fatty acid separation, even though they are usually utilised for particular studies (Supelco, 2001; Frega, unpublished results). Short polar GC columns (Carbowax20M; $15 \mathrm{~m} \times 0.32 \mathrm{~mm} \times 0.2 \mu \mathrm{m}$ film thickness), under isothermal conditions $\left(200^{\circ} \mathrm{C}\right)$ and $1.5 \mathrm{~mL} / \mathrm{min}$ of helium flow rate (Lercker 1983), have been used for a fast and simultaneous determination of the lipid content and the total fatty acid composition. This fast analysis (4 min/sample) allows the evaluation of 100 samples per day (Conte et al. 1989).

Analysis of free fatty acids, after methylation with diazomethane, can be also be performed in thermostable polar columns, which provides important information about lipid hydrolysis.

\subsection{Analysis of the unsaponifiable components}

Food lipids are mostly constituted by triglycerides, but about $1-3 \%$ of the total lipids are liposoluble components known as "unsaponifiable fraction or minor components". This unsaponifiable fraction is composed of hydrocarbons, carotenes, tocopherols, tocotrienols, linear fatty alcohols, triterpenic alcohols, methyl sterols, sterols and triterpenic dialcohols.

The qualitative and quantitative distributions of the unsaponifiable minor components are characteristic of the original lipid source (Morchio et al. 1989; Mariani et al. 1995; Cert et al. 2000) and they are useful for the identification of the lipid matrix from which they were extracted. In fact, the unsaponifiable minor components are utilised as fingerprint of most vegetable oils (Aparicio and Aparicio-Ruiz 2000).

The analysis of the unsaponifiable matter requires a previous lipid saponification, followed by TLC fractionation of the different components (Frega and Lercker 1985). The purified fractions are then silanized and usually analysed in non-polar GC columns. The silanized unsaponifiable matter can be

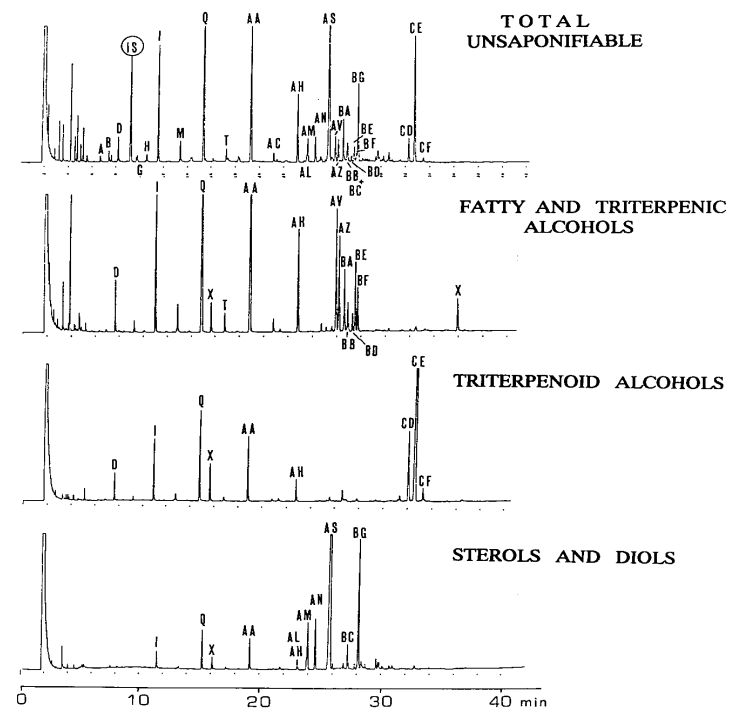

Figure 6

GC traces of total unsaponifiable matter and the TLC fractions of fatty and triterpenic alcohols, triterpenoid alcohols and sterols and diols, obtained from grape skin lipids. Note: Peak identification: A and B, unidentified; D, n-docosanol IS, internal standard; $\mathrm{G}, n$-tricosanol; $\mathrm{H}$, unidentified; I, $n$-tetracosanol; M, n-pentacosanol; Q, $n$-hexacosanol; T, n-heptacosanol: X, TLC impurities; AA, n-octacosanol; AC -nonacosan ; $\mathrm{H}$, $n$-nonacosanol; $\mathrm{AH}, \mathrm{n}$-tricontanol; $\mathrm{AL}, \mathrm{c}$, $\mathrm{AM}$, campesterol; AN, stigmasterol; AS, sitosterol; AV, AZ, BA,
$\mathrm{BB}, \mathrm{BD}, \mathrm{BE}$ and BF, triterpenic alcohols; BC, 7-avenasterol; BG, erythrodiol; CD, oleanolic acid (methyl ester); CE, oleanolic aldehyde; CF, methoxy maslinic acid (methyl ester). (From Frega et al. (1993b), with permission).

directly injected into a thermostable polar column (TAP), so as to perform a fast screening of the lipid components used as fingerprint of the food matrix (Figure 6) (Frega et al. 1993d). However, if a more accurate quantification of each series of components is required, it is advisable to separately inject the TLC fractions. GC conditions are the same as those indicated in the section of analysis of total lipids, except for the oven temperature program $\left(200^{\circ} \mathrm{C}\right.$ to $300^{\circ} \mathrm{C}$ at $3^{\circ} \mathrm{C} / \mathrm{min}$ ) and the injector and detector temperatures $\left(330^{\circ} \mathrm{C}\right)$. This fast screening of the unsaponifiable matter can provide the following information in $30 \mathrm{~min}:$ 1) a fingerprint of the unsaponifiable fraction which enables the differentiation among classes of components; and 2) feedback on the presence of marker components that indicate the quality of the raw material and evince unclaimed sample treatments. This type of analysis has been particularly useful for the study of olive oil and its admixtures with different oils, such as husk oil (Frega et al. 1993d). In addition, the method of olive oil extraction (pressing or chemical extraction) can be figured out by evincing the presence of erythrodiol, uvaol and oleanolic acid, which are quantitative markers of such processes (Frega et al. 1993d). This GC method also allows the 


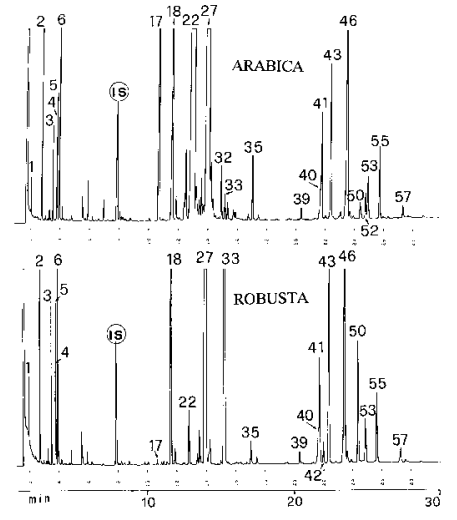

Figure 7

GC trace of the unsaponifiable fraction of the Arabica and Robusta coffee types, after methylation and silylation. Note: Peak identification: 1-6, fatty acid methyl esters; IS, internal standard (squalane); 17-37, diterpene alcohols [17) cafestol dehydration product, 18) kaweol dehydration product, 22) kaweol, 27) cafestol, 33) 16-O-methylcafestol]; 40, 22,23-dihydrobrassicasterol; 41 , campesterol; 43, stigmasterol; 46, sitosterol; 50, 5-avenasterol; 53, cycloartenol; 55 , 24-methylenecycloartanol; 57, citrostadienol. (From Frega et al. (1994), with permission)

separation of the oxidised products of squalene $\left(\mathrm{C}_{30} \mathrm{H}_{50}\right.$, triterpenic hydrocarbon), which denote the use of acid, low-quality olives for olive oil production.

The application of this fast screening to the total unsaponifiable matter of coffee lipids (Frega et al. 1994; Lercker et al. 1995) has provided a rapid methodology to quantify Robusta coffee in the Arabic coffee up to $5-7 \%$ (Frega et al. 1994). Figure 7 exhibits the profiles of the unsaponifiable fraction of the Arabica and Robusta coffees, obtained under the GC conditions aforementioned. This GC method has also been applied for the study of the changes on the lipid fraction extracted from high oleic sunflower seeds during ripening (Mozzon et al. 1998); a quantitative decrease of nearly all unsaponifiable components (except for the citrostadienol) was observed as the seeds ripened.

\subsubsection{Tocopherols and tocotrienols}

If the unsaponifiable matter is fractionated by silica TLC prior to GC analysis, attention must be paid to the fact that some tocopherols and tocotrienols can coelute with other components (such as epoxy-squalenes) (Lercker, 1986; Frega et al. 1993d) in the TLC band, due to their similar polarity. Tocopherols and tocotrienols can be efficiently separated with a short GC column coated with a medium polarity stationary phase (such as OV17). Good resolution of the TMS derivatives of tocopherols and tocotrienols is achieved in $6 \mathrm{~min}$, using an OV 17 open tubular supported glass (SCOT) column (15 m x 0.25 mm i.d. x 0.1-0.15 $\mu \mathrm{m}$ film thickness supported on $\mathrm{BaCO}_{3}$ ) under isothermal conditions $\left(240^{\circ} \mathrm{C}\right)$ and $2.5 \mathrm{~mL} / \mathrm{min}$ of helium flow rate (Lercker et al. 1981). Polar thermostable columns have also been used for the characterisation of the fatty-soluble antioxidant fraction of annatto (Frega et al. 1998); this fraction is quite peculiar if compared with other vegetable species, since it only contains tocotrienols (mainly $\delta$-tocotrienol) and completely lacks of tocopherols.

\subsubsection{Linear and triterpenic alcohols}

Linear and triterpenic alcohols TLC fractions can be well resolved when analysed in a thermostable polar column, as shown in Figure 6 (Frega et al. 1993d). The GC determination of linear alcohols without previous TLC fractionation of the unsaponifiable matter reduces errors due to sample handling (Frega et al. 1993d). This procedure can be employed for evincing the presence of husk oil in extra-virgin olive oil, even as low as $5 \%$ admixture. This GC method has also been applied for monitoring the alcohols fraction of high oleic sunflower seeds during ripening (Mozzon et al. 1998); a marked decrease in the percentage composition of the aliphatic alcohols was registered, with a simultaneous increase in the percentage composition of the triterpenic ones.

\subsubsection{Diterpenic alcohols}

The analysis of the TLC fraction of coffee diterpenic alcohols using thermostable polar GC columns, allows the determination of the presence of Robusta coffee $(5-10 \%)$ in coffee mixtures (Arabica and Robusta) (Figure 7) (Frega et al. 1994). This determination is not influenced by the geographical origin of the coffee bean, neither by the decaffeination process. In addition, the use of thermostable columns for the analysis of coffee lipids has enabled the identification of some components that arise from the dehydration of cafestol and dehydrocafestol during roasting (Lercker et al. 1995).

\subsubsection{Sterols (4-desmethylsterols)}

Sterols are usually analysed with non-polar capillary columns (Morchio et al. 1989; Frega et al. 1992, 1993d, 1994; Lercker et al. 1995; Mariani et al. 1995). However, thermostable polar columns (such as TAP) provide such an efficient separation of the sterol fraction (Frega et al. 1993a), that they have led to the identification of some components that overlapped under the analytical conditions used for the non-polar GC columns (Mariani et al. 1995). In particular, the peak that eluted at the retention time of campesterol in a non-polar column (SE52), was split into two peaks: campesterol and 22,23-dihydrobrassicasterol (Mariani et al. 1995). This result was of great importance because 22,23-dihydrobrassicasterol is almost twice as much as campesterol in certain oils, such as corn oil 


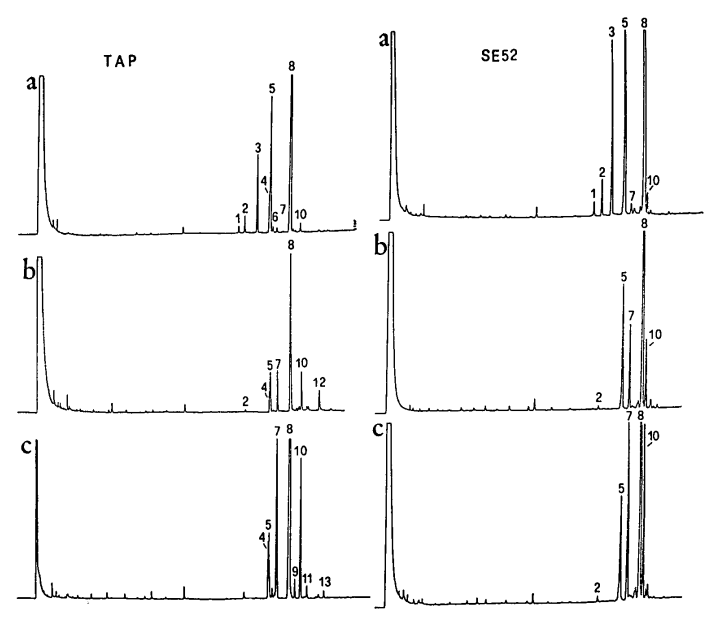

Figure 8

GC traces of the sterol fraction of illipe oil (a), peanut oil (b) and castor oil (c), injected into two columns of different polarity (TAP and SE52).

Note: Peak identification: 1, unknown; 2, cholesterol; 3, brassicasterol; 4, 22,23-dehydrobrassicasterol; 5 , campesterol; 6 , unknown 7, stigmasterol; 8, sitosterol; 9, unknown; 10, 5-avenasterol; 11,12 and 13, unknown. (From Frega et al. (1993a), with permission).

(Frega et al. 1993a). In addition, the separation of sitosterol and 5-avenasterol in a TAP column is better than that achieved with a SE52, being thus possible to detect other minor components between these two peaks (Frega et al. 1993a).

Figure 8 shows the chromatograms of the sterol fraction of illipe oil, peanut oil and castor oil, injected into TAP and SE52 columns. GC conditions for the TAP column are the same as those indicated in the section of analysis of total lipids, except for the oven temperature program $\left(200^{\circ} \mathrm{C}\right.$ to $300^{\circ} \mathrm{C}$ at $\left.3^{\circ} \mathrm{C} / \mathrm{min}\right)$ and the injector and detector temperatures $\left(330^{\circ} \mathrm{C}\right)$. The analysis performed on the SE52 column (25 $\mathrm{m} \mathrm{x}$ $0.32 \mathrm{~mm}$ i.d. $x 0.1 \mu \mathrm{m}$ film thickness) were run from $160^{\circ} \mathrm{C}$ to $300^{\circ} \mathrm{C}$ at $5^{\circ} \mathrm{C} / \mathrm{min}$ and both injector and detector temperatures were set up at $320^{\circ} \mathrm{C}$. Helium flow rate and split ratio were $0.8 \mathrm{~mL} / \mathrm{min}$ and $1: 80$, respectively. The TAP column has also been employed for detecting the presence of desterolised high-oleic sunflower oil (Mariani and Venturini 1997) and hazelnut oil (Mariani et al. 1999) in adulterated olive oils. This column has been also useful for evincing presence of ergosterol in high-acidity olive oils, which in some cases is the main sterol after sitosterol (Mariani 1998). Other sterols were detected in these types of olive oils, one of which presented a similar structure to that of ergosterol (with an additional unsaturation) and displayed a retention time similar to that of brassicasterol in a SE52 column (Mariani 1998). In case levels of brassicasterol higher than $1 \%$ are found in olive oils, it is advisable to perform GC analysis on a TAP column in order to verify the correct identification and quantification of these minor sterols.

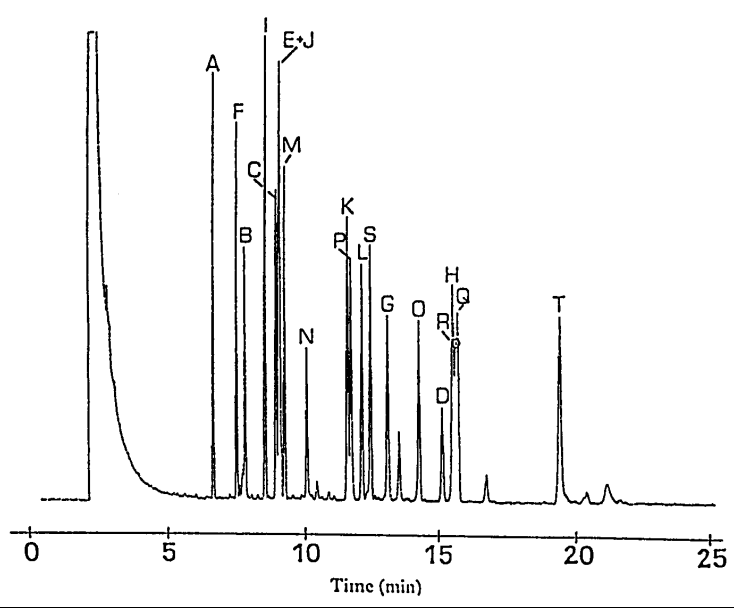

Figure 9

GC trace of the TMS derivatives of a standard mixture of cholesterol oxidation products (COPs or oxycholesterols). Note: Peak identification: A, $5 \alpha$-cholestane; B, cholesta-3,5-diene; $\mathrm{C}$, dihydrocholesterol, D, cholesta-3,5-diene-7-one; E, cholesterol; F, 7 $\alpha$-hydroxycholesterol; G, 4-cholesten-3-one; H, 5-cholesten-3-one;

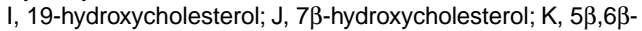

epoxycholesterol; L, $5 \alpha, 6 \alpha$-epoxycholesterol; M, 4 4 -hydroxycholesterol;

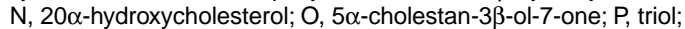
$\mathrm{Q}, 5 \alpha$-cholestan-3 3 -ol-6-one; R, $7 \beta$-ketocholesterol; S, 25-hydroxycholesterol; T, cholestan -3 $\beta, 5 \alpha$-diol-6-one (From RodriguezEstrada et al. (1998), with permission).

The analysis of the TLC fraction of sterols with the TAP column, allows determining the presence of the Robusta coffee (at least 20\%) in coffee mixtures (Arabica and Robusta) (Frega et al. 1994). The application of polar thermostable columns to the study of the lipid fraction extracted from high oleic sunflower seeds during ripening has evinced a singular behaviour of 7-stigmastenol (Mozzon et al. 1998); in fact, the ratio of 5-avenasterol to 7-stigmastenol is reversed during ripening.

\subsubsection{Sterol oxidation products}

The analysis of sterol oxidation products requires a lipid cold saponification, followed by an enrichment/purification step with either silica or amino propyl solid-phase extraction (Rose-Sallin et al. 1995; Guardiola et al. 1998; Ulberth and Rossler 1998). This procedure removes most of the unoxidised sterols, which overlap with some of their oxidation products. Although both plant and animal sterols are prone to oxidation, most studies have been focused on cholesterol oxidation products due to their asserted toxicity and biological activity (Schroepfer 2000).

Most GC analyses of sterol oxidation products are performed on non-polar columns (Sanders et al. 1989; Rodriguez-Estrada et al. 1998). However, good peak resolution can be also achieved with a thermostable polar column (TAP) (RodriguezEstrada et al. 1998), so providing an analytical alternative in case of matrix interference. Figure 9 shows the chromatogram of a standard mixture of 
oxycholesterols injected into a TAP column (see specifications in the section of Analysis of total lipids). Oven temperature was programmed from $230^{\circ} \mathrm{C}$ to $260^{\circ} \mathrm{C}$ at $2.5^{\circ} \mathrm{C} / \mathrm{min}$ and then taken to $290^{\circ} \mathrm{C}$ at $1^{\circ} \mathrm{C} / \mathrm{min}$. Both injector and detector temperatures were set up at $325^{\circ} \mathrm{C}$. Helium inlet pressure and split ratio were $85 \mathrm{kpa}$ and 1:50, respectively.

In conclusion, many gas chromatographic determinations that were traditionally performed on non-polar columns could be also carried out with polar thermostable GC columns, which provide excellent separations. This type of columns can be used for a fast screening of the total unsaponifiable matter of the oil or lipid extract. In addition, they can generate GC traces with different separation characteristics, which can lead to the identification of components that cannot be completely resolved with non-polar GC columns.

\section{REFERENCES}

Aparicio, R., Aparicio-Ruiz, R. (2000) Authentication of Vegetable Oils by Chromatographic Techniques. J. Chromatogr., 881, 93-104

Cert, A., Moreda, W., Pérez-Camino, M.C. (2000). Chromatographic analysis of minor constituents in vegetable oils. J. Chromatogr., 881, 131-148.

Conte, L.S., Leoni, Q., Palmieri, S., Capella, P., Lercker, G. (1989). Half-seed analysis: rapid chromatographic determination of the main fatty acids of sunflower seed. Plant Breeding, 102, 158-165.

Dong, M.W., Dicesare, J.L. (1983). Improved separation of natural oil triglycerides by liquid chromatography using columns packed with 3- $\mu \mathrm{m}$ particles. J. Amer. Oil Chem. Soc., 60, 788-791.

Frega, N., Bocci, F., Conte, L.S., Testa, F. (1991). Chemical composition of tobacco seeds (Nicotiana tabacum L.). J. Amer. Oil Chem. Soc., 68, 29-33.

Frega, N., Bocci, F., Giovannoni, G., Lercker, G. (1993a). High resolution GC of unsaponifiable matter and sterol fraction in vegetable oils. Chromatographia, 36, 215-217.

Frega, N., Bocci, F., Lercker, G. (1990). The HRGC determination of triglycerides. Ital. J. Food Sci., 4, 257-264.

Frega, N., Bocci, F., Lercker, G. (1992). Direct gas chromatographic analysis of the unsaponifiable fraction of different oils, by using a polar capillary column. J. Amer. Oil Chem. Soc., 69, 447-450.

Frega, N., Bocci, F., Lercker, G. (1993b). High resolution gas chromatographic method for cuticular lipid determination of grape berries. In Proceedings of XV Int. Symposium on Capillary Chromatography, Riva del Garda (Italy), pp. 1237-1242.

Frega, N., Bocci, F., Lercker, G. (1993c). High-resolution gas-chromatographic determination of diacylglycerols in common vegetable oils. J. Amer. Oil Chem. Soc., 70, 175-177.

Frega, N., Bocci, F., Lercker, G. (1993d). High-resolution gas chromatographic determination of alkanols in oils extracted from olives. J. Amer. Oil Chem. Soc., 70, 919-921.

Frega, N., Bocci, F., Lercker, G. (1993e). Acidi grassi liberi e diacilgliceroli quali parametri di qualità degli oli extra vergini di oliva. Riv. Ital. Sostanze Grasse, 70, 153-155.
Frega, N., Bocci, F., Lercker, G. (1994). High resolution gas chromatographic method for determination of Robusta coffee in commercial blends. J. High Resol. Chromatogr., 17, 303-307.

Frega, N., Mozzon, M., Bocci, F. (1998). Identification and estimation of tocotrienols in the annatto lipid fraction by gas chromatography-mass spectrometry. J. Amer. Oil Chem. Soc., 75, 1723-1727.

Guardiola, F., Jordan, A., Grau, A., Garcia, S., Boatella, J., Rafecas, M., Codony, R. (1998). Recent methodological advances in oxysterol determination. Recent Res. Devel. Oil Chem., 2, 77-88.

Lercker, G. (1983). Short capillary columns in the analysis of lipids. J. Chromatogr., 279, 543-548.

Lercker, G. (1986). Recenti acquisizioni analitiche nel settore delle sostanze grasse. Riv. Ital. Sostanze Grasse, 63, 331-340.

Lercker, G., Frega, N., Bocci, F., Rodriguez-Estrada, M.T. (1995). High resolution gas chromatographic determination of diterpenic alcohols and sterols in coffee lipids. Chromatographia, 41, 29-33.

Lercker, G., Frega, N., Bocci, F., Servidio, G. (1994). "Veiled" extra-virgin olive oils: dispersion response related to oil quality. J. Amer. Oil Chem. Soc., 71, 657-658.

Lercker, G., Frega, N., Capella, P., Conte, L.S. (1981). La gascromatografia su colonne capillari (HRGC) nello studio dell' insaponificabile degli oli vegetali. Riv. Ital. Sostanze Grasse, 58, 324-330.

Lercker, G., Moschetta, M., Caboni, M.F., Frega, N. (1985). Determinazione degli oli esterificati negli olii provenenti dalla lavorazione delle olive. Riv. Ital. Sostanze Grasse, 62, 15-18.

Mariani, C. (1998). Sulla presenza di ergosterolo negli oli di oliva. Riv. Ital. Sost. Grasse, 75, 3-10.

Mariani, C., Bellan, G., Grob, K. (1995). Sulla complessità della frazione sterolica delle sostanze grasse. Riv. Ital. Sostanze Grasse, 72, 97-104.

Mariani, C., Bellan, G., Morchio, G., Pellegrino, A. (1999). I componenti minori liberi ed esterificati dell'olio di oliva e dell'olio di nocciola: loro possibile utilizzo nell'individuazione di commistioni. Nota 1. Riv. Ital. Sostanze Grasse, 76, 59-68.

Mariani, C., Venturini, S. (1997). Individuazione dell'olio di girasole ad alto oleico desterolato nell'olio di oliva. Nota 2. Riv. Ital. Sostanze Grasse, 74, 489-500.

Morchio, G., Amelotti, G., Bocca, A., Bovio, V., Conte, L., Cozzoli, O., Cremonesi, L., Fascioli, R., Giro, L., Grieco, D., Lercker, G., Mariani, C., Pierattini, G., Sarti, E., Zunin, P. (1989). Analisi gascromatografica degli steroli con l'impiego di colonne capillari. Risultati di una sperimentazione interlaboratorio. Riv. Ital. Sostanze Grasse, 66, 531-538.

Mozzon, M., Bocci, F., Frega, N. (1998). A study on the lipidic fraction extracted from high oleic sunflower seeds (Helianthus annuus L.) during the ripening process. J. Agric. Food Chem., 46, 4198-4202.

EC. (1991). On the characteristics of olive oils and kernel olive oils and on their methods of analysis. Regulation 2568/11.7.91. Off. J. Eur. Communities. L.248

Palmer, A.J., Palmer, F.J. (1989). Rapid analysis of triacylglycerols using high-performance gas chromatography with light scattering detection. J. Chromatogr., 465, 369-377.

Penazzi, G., Rodriguez-Estrada, M.T., Lercker, G. (1996). Routine CGC determination of hydrolytic alterations of deep-fat frying oils. In Proceedings of XVIII Int. Symposium on Capillary Chromatography, Riva del Garda (Italy), pp. 1287-1292. 
Rodriguez-Estrada, M.T., Caboni, M.F., Costa, A., Lercker, G. (1998). Gas chromatographic analysis of cholesterol oxidation products on a thermostable medium capillary column. J. High Res. Chromatogr., 21, 509-512.

Rose-Sallin, C., Huggett, A., Bosset, J.O., Tabacchi, R., Fay, L.B. (1995). Quantification of cholesterol oxidation products in milk powders using $\left[{ }^{2} \mathrm{H}^{7}\right]$ cholesterol to monitor cholesterol autoxidation artifacts. J. Agric. Food Chem., 43, 935-941.
Sanders, D.B., Addis, P.B., Park, S.W., Smith, D.E. (1989). Quantification of cholesterol oxidation products in a variety of foods. J. Food Protection, 52, 109-114.

Schroepfer, G.J. (2000). Oxysterols: modulators of cholesterol metabolism and other processes. Physiological Reviews, 80, 361-554.

Supelco. (2001). Cromatografia-Prodotti per l'analisi e la purificazione. p.18

Ulberth, F., Rossler, D. (1998). Comparison of solid-phase extraction methods for the cleanup of cholesterol oxidation products. J. Agric. Food Chem., 46, 2634-2637. 